\title{
A. MELANOSOME-DISPERSING SUBSTANCE IN THE BLOOD AND URINE OF PATIENTS WITH RETINITIS PIGMENTOSA (Preliminary Communication)
}

BY

\section{E. CunNingham DaX}

(ASSISTANT MEDICAL OFFICER LEAVESDEN HOSPITAL, HERTS.)

IN recent years there has been an increasing tendency to associate retinitis pigmentosa with pituitary dysfunction or diencephalic disturbance.

Such a relationship might be anticipated on embryological grounds from the common development of the optic vesicles and the diencephalon.

Clinical evidence gives further support to this connection. In the Laurence-Moon-Biedl syndrome retinitis pigmentosa is associated with obesity, hypogenitalism, polydactylism and mental deficiency, all probably indicating the manifestation of a specific hypophyso-diencephalic disturbance. At present the pathological evidence for a morbid process causing the syndrome is disappointing.

Although Stör in 1865 described a case which was probably an example of the above syndrome, and Fröhlich in 1901 described dystrophia adiposo-genitalis, none of Bell's three hundred odd references to the literature of retinitis pigmentosa; up to 1922 , drew any special attention to a relationship between this condition and the pituitary body. In the last ten years an increasing number of papers have emphasised the association, in particular those of Zondek. He believes that abnormal hormonal influences from the pituitary body are probably produced by some interference in its co-ordination with the hypothalamus, resulting in the condition of retinitis pigmentosa. In collaboration with Koehler he gives evidence that cases showing pigmentary retinal degeneration without other abnormal clinical signs exhibit metabolic characteristics typical of his diencephalic syndrome (diencephalopathy).

Viallefont gives a brief summary of the evidence for the pituitary origin of retinitis pigmentosa, in which he believes, and describes the treatment of four cases with an extract of the whole pituitary gland; he was able to find four other accounts of similar treatment.

Recent Italian papers suggest an endocrine origin for retinitis pigmentosa, but none limits it to a diencephalo-hypophyseal disturbance. Most of the writers regard retinitis pigmentosa as being caused by hormonal action upon the local circulation, and suggest 
that treatment with parasympathetic stimulants and vaso-dilators gives the best results.

Mecca observed five patients with retinitis pigmentosa for two years, and four of these showed abnormalities of the sella turcica and signs of neuro-endocrine disturbance. As a result of the study of these five and nine older cases he believes the main pathogenic factor is a spasm of the retinal vessels, due to endocrine action. Rinaldi holds much the same views, but thinks that independent functional or organic changes in the vessels of the retina or choroid may cause the condition.

Farina believes retinitis pigmentosa is probably due to a polyglandular endocrine disturbance. Schupfer, too, makes a critical survey of the literature. He holds the view that the diencephalohypophyseal theory alone cannot explain certain facts, such as the disturbances of smell and hearing and various congenital abnormalities of organs and tissues, not of ectodermal origin, which are found in many cases of retinitis pigmentosa. He concludes that inherited degenerative disturbances, especially of the mesodermal layer, play an important part in the pathogenesis of retinitis pigmentosa.

In contrast to the number of clinical observations there is little experimental evidence in support of an endocrine origin for retinitis pigmentosa. Some work is here described which suggests that a disorder of pituitary function is present in this condition.

In July, 1937, the writer undertook a classification of the various types of cutaneous pigmentation in this hospital, and samples of urine from selected cases were injected into frogs or toads, on the assumption that it might be possible to show the presence of a melanophore " expanding" substance. Later, working in conjunction with W. D. Brown, experiments were made with the urine from pregnant women. The method was next applied to two cases of the Laurence-Moon-Biedl syndrome in this hospital, and as both yielded positive results another six patients with retinitis pigmentosa were examined.

Method.-Jores and Will showed that "activation" of the melanosome-dispersing hormone of the pituitary body took place in alkaline extracts, and that if such solutions were boiled the potency was increased. Light is said to inactivate the hormone, particularly in acid solution. Therefore freshly passed urine was made just alkaline to litmus with tenth-normal caustic soda, immersed in a boiling bath for half an hour, and placed in a dark cupboard to cool.

The frogs were sorted according to their colour and size. Depending upon these factors the volume of urine given to each animal varied from 0.3 to 1 c.c., but was constant for all the frogs of any batch. The injections were made into the dorsal lymph sac. 
One frog in each group received saline, and a second urine from a control. The control urines were selected at random by the nurses, and prepared in the same way as those of the patients with retinitis pigmentosa. Identification of the frogs was effected by coloured silks tied round their hind limbs. They were kept in daylight against a white background. After the method had been conclusively shown to succeed with intact animals, decerebrate frogs were used.

Results.-1. At first the experiments were performed without making any permanent record of the results. The following table shows the degree of colour change compared with the controls, 0 signifying a negative result, 1 an appreciable darkening, 2 a fairly deep colour, and 3 that the frog turned practically black. The letters in the vertical column represent the patients with retinitis pigmentosa whose urines were used.

\section{INJECTIONS}

\begin{tabular}{c|c|c|c|c|c|c|c}
\hline & $\mathrm{a}$ & $\mathrm{b}$ & $\mathrm{c}$ & $\mathrm{d}$ & $\mathrm{e}$ & $\mathbf{f}$ & $\mathrm{g}$ \\
\hline $\mathrm{A}$ & 1 & - & 2 & 2 & - & 1 & 3 \\
$\mathrm{~B}$ & 2 & 2 & 1 & 1 & 0 & 1 & 0 \\
$\mathrm{C}$ & 1 & - & 0 & 1 & 2 & 0 & - \\
$\mathrm{D}$ & 1 & - & 2 & 2 & 2 & 0 & 1 \\
$\mathrm{E}$ & 2 & - & 1 & 2 & - & 0 & 2 \\
F & - & - & 1 & 1 & - & 1 & - \\
G & - & 1 & - & 1 & 2 & 0 & 3 \\
H & - & 1 & 3 & 2 & 1 & 1 & 2 \\
\hline
\end{tabular}

A and B are female cases of the Laurence-Moon-Biedl syndrome with well marked retinitis pigmentosa, $\mathrm{C}$ is a woman with all the signs of this syndrome except polydactylism. D is a female idiot with familial cerebellar hypoplasia and retinitis pigmentosa lately described by R. M. Stewart. E is a feeble-minded deafand-dumb girl with an extremely small sella turcica, as seen by $\mathrm{X}$-ray examination; $\mathrm{F}$ a deaf, dumb and almost blind patient ; $G$ an idiot without obvious pituitary abnormality ; and $\mathrm{H}$ an epileptic idiot. These last three cases are males.

It will be seen that the effects of injection were not constant, whereas on one occasion a frog would be turned very dark, on another the same patient's urine only produced a slight result, although there was usually a definite change compared with the controls. The results using large and very light-coloured frogs (injection " $f$ " in the above table) were less impressive than in 
slightly darker, smaller animals. Toads showed the melanosome dispersion easily, but the facility with which they changed colour of their own accord made them more difficult to use. The darkening took two to three hours to reach a maximum, and lasted a variable length of time from two up to twenty-four hours.

2. Photographs were taken of the frogs, the urines injected, and after two to three hours when the colour had changed they were photographed again. An example is shown in Plate 1.

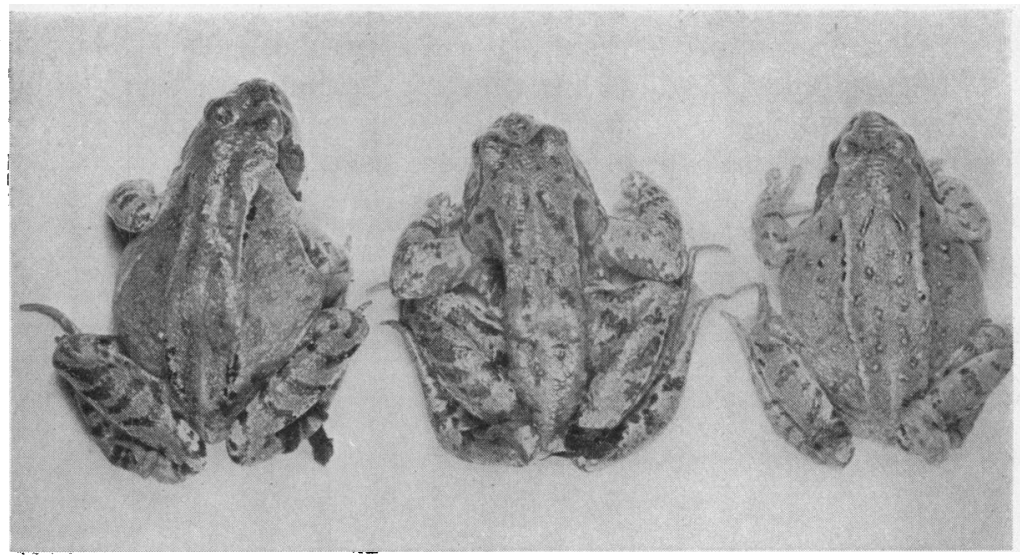

Plate 1. Fig. 1.

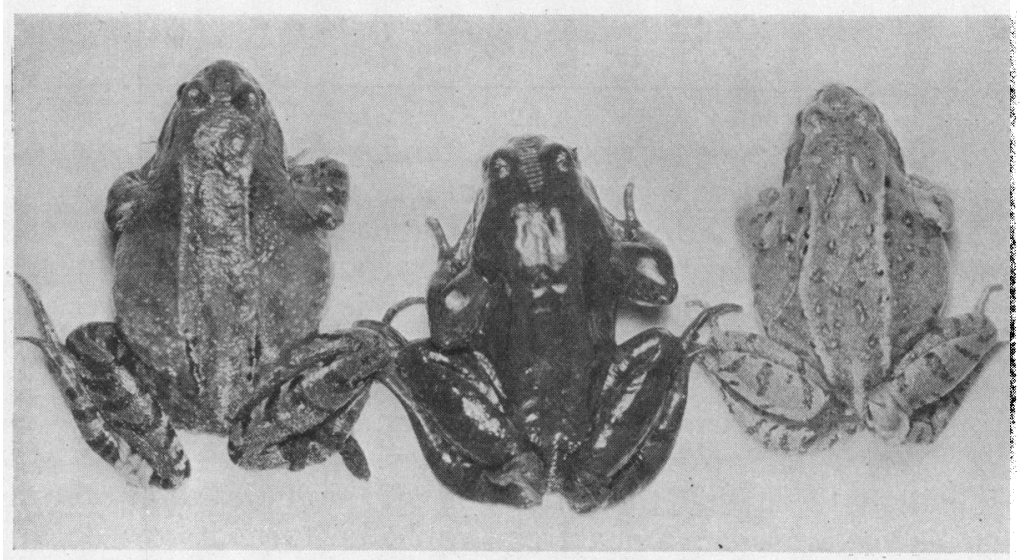

Plate 1. Fig. 2.

The first photograph was taken before and the second two and a quarter hours after the injection of urine. The animal on the right was a control. 




Plate 2. Fig. 1.

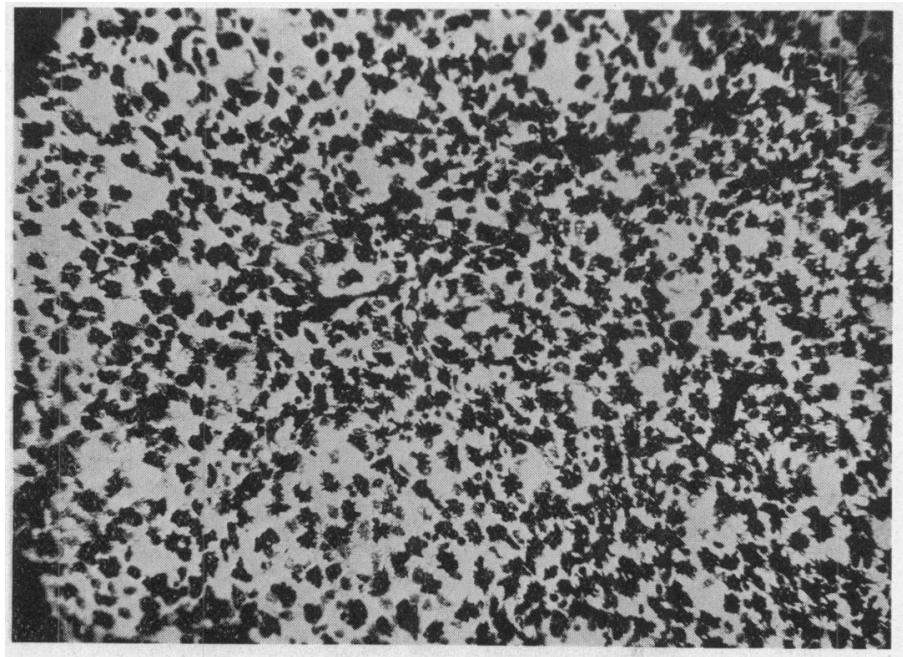

Plate 2. Fig. 2.

Two low power photographs of skin from toads injected with urine, the first from a control, the second from a case of retinitis pigmentosa. 


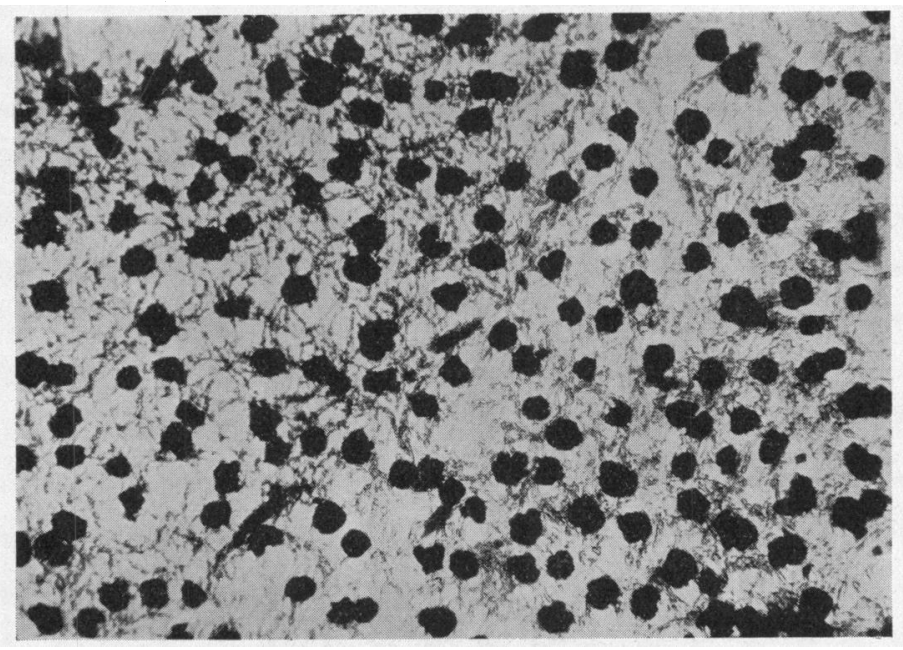

Plate 2A. Fig. 1.

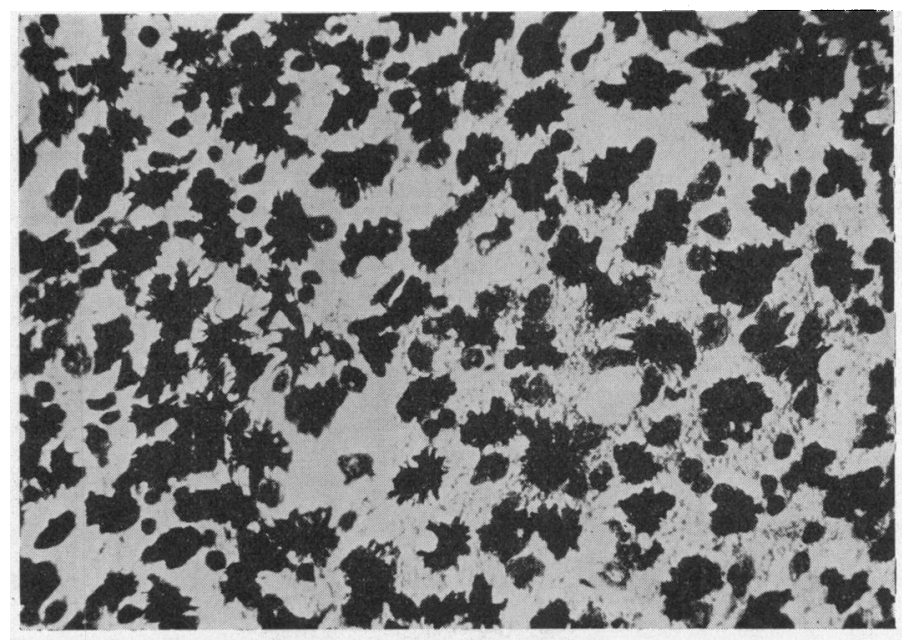

Plate 2a. Fig. 2.

These are similar to Plate 2, but seen under high power.

Photographs by F. R. Hill. 
3. Pairs of similar frogs were chosen, one injected with a control urine and the other with that from a case of retinitis pigmentosa. When melanosome dispersion had occurred they were killed, the skin removed, corresponding portions pinned to cork, and foated in either "frogs'" saline, glycerine, absolute alcohol, xylol, a solution of salicylic acid or formol-saline.

Some preparations were made by mounting directly, and some pieces were sectioned between liver to a thickness of $25 \mu$. A photograph of a flat preparation is shown in Plate 2. The sections showed the melanophores as a series of discrete black masses in the control, whilst in the other there was an almost continuous line of pigment, the melanophores being less distinct.

4. Blood from these patients was freed from protein by introducing one volume into three of absolute alcohol. It was shaken, then allowed to stand over-night. The clear supernatant fluid was next removed, one volume of water was added, and the alcohol boiled off. The results of injection of 1 c.c. of this extract were variable like those of the urines, though usually constant for all the cases of retinitis pigmentosa. The skin, however, darkened more rapidly, often attaining its maximum depth of colour in one and a half hours, and the effect lasted longer than when urine was used.

5. Cerebro-spinal fluid from both the cisterna magna and the lumbar region was injected, but no melanophore expansion was seen, even when 2 c.c. were used.

6. Frogs were killed and from each, correspondingly situated pieces of skin were excised, pinned to cork, and floated in experimental and control urines respectively. After standing over-night the skin was removed from the urine, placed in absolute alcohol, and later cleared in xylol and mounted in balsam. A distinct difference in colour between the two specimens was now seen, and on microscopical examination a melanosome-dispersion was visible in the one but not in the other. The effect was sometimes seen microscopically in the one piece of skin even when injection of the same experimental urine into a frog had not produced an appreciable darkening.

Discussion.- It would appear from these observations that eight adult mental defectives with retinitis pigmentosa have a substance present in their blood and urine which is capable of dispersing the melanosomes of the frog. It could not be detected in either the cisternal or lumbar cerebro-spinal fluid by the method used.

From no other patients have samples of urine been found which give a similar result with the exception of certain cases of pregnancy, perhaps abnormal pigmentation of the skin, hyperthyroidism, and pituitary disease (Collin and Drouet, Jones). 
Three of the eight have signs of pituitary dysfunction in addition to retinitis pigmentosa.

Collin and Drouet reported a melanosome-dispersing substance to be present in the urine on the day before or on the first day of menstruation. The above results do not apply to the urines collected on these days from the two females who menstruate.

It is known that a melanophore " expanding" hormone is found in the pituitary body but in no other tissue. The urine has not been shown to contain a substance capable of dispersing the melanosomes of the frog except in pathological conditions of the pituitary body, or at periods in which this gland is subjected to physiological stress. Thus from the little that is known concerning the substance found in the blood and urine of these cases of retinitis pigmentosa, it would appear probable that it is a hormone derived from the pituitary body.

Summary. - The blood and urine of eight adult mental defectives with retinitis pigmentosa contains a substance which will disperse the melanosomes of the frog.

A similar effect can be produced by the urine when there is pituitary abnormality or when the gland is subjected to physiological stress, but not in other conditions.

The evidence suggests that the substance in the blood and urine from these cases of retinitis pigmentosa is of pituitary origin.

I would like to thank Dr. R. M. Stewart, the Medical Superintendent, for suggesting the application of the method to these cases, for his help, and for allowing me to use the clinical material.

\section{REFERENCES}

BELL, J. (1922)-Treasury of Human Inheritance II, pt. I.

Collin, R., and Drouet, P. L. (1933)-Bull. Acad. Med., Paris, Vol. CIX, p. 794 .

*FARINA, F. (1936)-Rass. Ital. d'Ottal., Vol. III, p. 566.

JONES, E. I. (1938)-Lancet, Vol. I p. 11.

JoRes. A., and WILL, G. (1934)-Z. ges. exp. Med., Vol. XCIV, p. 389.

* MeccA, M. (1936)-Ann. di Ottal., Vol. CLXXII.

* (1936)-Atti Cong. Soc. Ottal. Ital., p. 415.

* RiNaldi, S. (1937)-Rif. med., Vol. LIII, p. 371.

*SCHUPFER, F. (1937)-Boll. d'ocul., Vol. XVI, p. 425.

Stewart, R. M. (1937)-Sect. Neurol. R. Soc. Med., February 18.

STÖR, A. (1865).-Klin. Monatsbl.f. Augenheilk., Vol. III. p. 23 (per J. Bell).

VAN DYKE, (1936)-Physiology and Pharmacology of the Pituitary Body. Chicago.

ViallefoNT H. (1936)-Ann. d'Ocul., Vol. CLXXIII, p. 33.

ZONDEK, H. (1935)-Diseases of the endocrine glands. London. and KoEHLER, G. (1932)-Deutsch. med. Wochenschr., Vol. LVIII, p. 2025.

*Abstracts of these papers appeared in Zbl.f.d. ges. Ophthal. 1936-37. 